Check for updates

Cite this: RSC Adv., 2018, 8, 35776

\title{
Enhanced electrochemical response of a modified glassy carbon electrode by poly(2-vinlypyridine- $b$ - methyl methacrylate) conjugated gold nanoparticles for detection of nicotine $\uparrow$
}

\author{
Sana Rahim, Asma Rauf, Saba Rauf, Muhammad Raza Shah \\ and Muhammad Imran Malik (D)*
}

Poly(2-vinylpyridine- $b$-methylmethacrylate) coated gold nanoparticles [P(2VP-MMA)-AuNPs] were prepared and characterized by UV-Vis, FTIR, AFM, and zetasizer analysis. Investigation of the potential of the synthesized poly(2-vinylpyridine- $b$-methylmethacrylate) coated gold nanoparticles [P(2VP-MMA)AuNPs] for detection of nicotine is the main focus of the current study. P(2VP-MMA)-AuNPs were coated on a glassy carbon electrode (GCE) for electrochemical detection of nicotine by cyclic voltammetry. The effect of molar mass of individual P2VP blocks and total molar mass of the block copolymer is evaluated in the context of an enhanced electrochemical response of the modified GCE for its sensing ability of nicotine in both aqueous and organic media. The electrochemical detection of nicotine is significantly enhanced by modification of the GCE with P(2VP-MMA)-AuNPs.

Received 16th August 2018

DOI: $10.1039 / \mathrm{c} 8 \mathrm{ra06857g}$

rsc.li/rsc-advances

spectrophotometry, ${ }^{16}$ capillary electrophoresis (CE), ${ }^{17}$ spectrofluorimetry, Raman spectroscopy, ${ }^{\mathbf{1 8}}$ radioimmunoassay, and electroanalytical assay with different electrode systems have been reported for the determination of nicotine. ${ }^{\mathbf{1 7 1 9 , 2 0}}$ The above-mentioned analytical methods possess several advantages; nonetheless, the applicability of these methods for routine analysis is impeded by tedious sample preparation procedures for preliminary extraction and purification of nicotine that often lead to sizeable loss of analyte and prolonged analysis time. Furthermore, hi-tech and expensive instrumentation is required.

Linear-scan voltammetry and cyclic voltammetry are efficient techniques which have been employed for decades for generating mono- and dianions/diradicals (i.e., anions or cations) and for studying their subsequent reactions. Cyclic voltammetry (CV) is perhaps one of the most practiced electroanalytical techniques owing to its simplicity of operation and versatility of applications in diverse disciplines such as inorganic chemistry, organic chemistry, and biochemistry. ${ }^{21-23}$ Cyclic voltammetry allows for detailed study of the kinetics as well as thermodynamics of radical formation and reactions. Besides these obvious advantages, one of the foremost obstacles in investigating complex molecules and/or (bio)mixtures via cyclic voltammetry is the limited sensitivity of conventional electrodes. Moreover, the oxidation/reduction of nicotine and its metabolites requires an extremely large potential window which is generally out of the range of conventional electrodes. ${ }^{23}$ Therefore, modification of the electrode is often a prerequisite to enhance the detecting (sensing) efficiency of an electrode.

H. E. J. Research Institute of Chemistry, International Centre for Chemical and Biological Sciences (ICCBS), University of Karachi, Karachi 75270, Pakistan. E-mail: mimran.malik@iccs.edu

$\dagger$ Electronic supplementary information (ESI) available. See DOI: 10.1039/c8ra06857g

(GC), ${ }^{10,13}$ liquid chromatography-mass specimmunochromatography, ${ }^{15}$ 
Several reports on the modification of a glassy carbon electrode (GCE) for determination of nicotine by cyclic voltammetry have been presented. A boron-doped diamond electrode to improve the separation of nicotine peak in alkaline media using a potential window from +0.6 to $+1.8 \mathrm{~V}$ was reported by Suffredini $e t$ al. ${ }^{20}$ A screen printed electrode modified by metallic free carbon nanotube cluster was employed for the detection of nicotine in artificial saliva in a potential range of -0.4 to $+1.2 \mathrm{~V} .^{24}$ The effects of thin-layer diffusion in the electrochemical detection of nicotine on multi-walled carbon nanotubes modified basal plane pyrolytic graphite (MWCNT-BPPG) electrode at a potential range of 0.0 to $+1.0 \mathrm{~V}$ was evaluated. ${ }^{25}$ In another study, nanocarbon was employed as an alternative to multi-walled carbon nanotubes with modified electrodes using potential range of -1.5 to $+1.5 \mathrm{~V} .{ }^{26}$ Nicotine was determined in tobacco samples based on mussel-inspired reduced graphene oxidesupported gold nanoparticles at a potential range of -0.2 to $+0.6 \mathrm{~V} .^{27}$

Gold nanoparticles (AuNPs) have gained extensive consideration in recent years due to their remarkable optical properties and their use for different applications including photocatalysis ${ }^{28-32}$ SERS sensing, ${ }^{33,34}$ storage devices, ${ }^{35-37}$ sensing, ${ }^{38-40}$ etc. In our recent publications, stabilization and applications of NPs by homo and copolymers of P2VP has been demonstrated. ${ }^{40,41}$ In this study, gold nanoparticles (AuNPs) stabilized by poly(2-vinylpyridine-block-methyl methacrylate) [P2VP- $b$-PMMA or P(2VP-MMA)] modified glassy carbon electrode i.e. [P(2VP-MMA)-AuNPs]-GCE, is used as a valuable tool to study the electrochemical behaviour of nicotine in aqueous as well as in organic media. $\mathrm{P}$ (2VP-MMA)-AuNPs were synthesized and characterized by UV-Vis, FTIR, AFM and zetasizer. Further, the prepared P(2VP-MMA)-AuNPs were coated on GCE for preparation of [P(2VP-MMA)-AuNPs]-GCE. Polymer stabilized nanoparticlesmodified electrode offers high effective surface area, enhanced mass transfer and better control over local microenvironment. The large effective surface area results in more active sites and higher signal to noise ratio. Higher rate of mass transport to the electrode surface is expected due to smaller dimensions of nanoparticles. To the best of our knowledge, current study is perhaps the first report on the enhancement of electroanalytical response for nicotine by employing [P(2VP-MMA)-AuNPs] modified glassy carbon electrode.

\section{Experimental section}

\subsection{Materials}

Poly(2-vinylpyridine-block-methyl methacrylate) [P2VP- $b$-PMMA or $\mathrm{P}$ (2VP-MMA)] block copolymers of various molar masses were purchased from polymer standards services (Mainz, Germany). The specifications of the products as provided by the manufacturer are listed in Table 1. Tetrachloroauric(III) acid trihydrate $>99.9 \%\left(\mathrm{HAuCl}_{4} \cdot 3 \mathrm{H}_{2} \mathrm{O}\right)$ (Sigma Aldrich, USA) was used for the synthesis of gold nanoparticles. $\mathrm{NaBH}_{4}>95.0 \%$ (TCI, Tokyo, Japan), and HPLC grade solvents such as methanol $>99.9 \%$, and toluene $>99.9 \%$ (RCI Labscan Limited, Thailand) were used as received.

Deionized water (DIW) was taken from ICCBS distillation plant. Acetonitrile (ACN) $>99.99 \%$ (Fisher scientific, USA) was dried over $3 \AA$ molecular sieves to remove the traces of water prior to use. Standard nicotine $\geq 99.0 \%$ was purchased from Fluka Chemie Gmbh (Buchs, Switzerland). Two supporting electrolytes (SE), tetra- $n$-butyl ammonium perchlorate (TBAP) $>99.0 \%$ (TCI, Tokyo, Japan) and potassium chloride (KCl) $>99.0 \%$ (Merck, Germany), were used for non-aqueous and aqueous medium, respectively. Silver nitrate $\left(\mathrm{AgNO}_{3}\right)>99.99 \%$ (Scharlau, Europe) was used for the preparation of $\mathrm{Ag} / \mathrm{Ag}^{+}$ reference electrode. All electrochemical experiments were carried out at ambient temperature (i.e. $28 \pm 1{ }^{\circ} \mathrm{C}$ ).

\subsection{Instrumentation}

UV-visible spectra were recorded with a double beam Shimadzu UV-1800 series spectrophotometer (Kyoto, Japan) operated at $1 \mathrm{~cm}$ path length quartz cuvette. The wavelength range from 190 to $800 \mathrm{~nm}$ was used.

The FTIR spectra were recorded on a Bruker Vector 22 spectrometer (Germany) by $\mathrm{KBr}$ pellet method. Analyses of all samples were performed in the range of $400-4000 \mathrm{~cm}^{-1}$. Ten scans were recorded in order to obtain the spectral resolution of $0.1 \mathrm{~cm}^{-1}$.

The size of P(2VP-MMA)-AuNPs were determined by atomic force microscopy (AFM) using an Agilent 5500 microscope (Arizona, USA), equipped with triangular silicon nitride cantilever (Veeco, model MLCT-AUHW) with a spring constant of $0.01 \mathrm{~N} \mathrm{~m}^{-1}$ and $0.1 \mathrm{~N} \mathrm{~m}^{-1}$, operated in a tapping mode. Samples were prepared by putting a drop of freshly prepared solution on a surface of silicon (Si) wafer, and dried in air.

Particle size distribution and zeta potential of P(2VP-MMA)AuNPs were determined by zetasizer, Nano-ZSP (Malvern

Table 1 Molecular weight and polydispersity index of P(2VP-MMA), as provided by manufacturer ${ }^{a}$

\begin{tabular}{|c|c|c|c|c|c|}
\hline Sample & $M_{\mathrm{n}}\left(\mathrm{g} \mathrm{mol}^{-1}\right)$ & $M_{\mathrm{w}}\left(\mathrm{g} \mathrm{mol}^{-1}\right)$ & $M_{\mathrm{p}}\left(\mathrm{g} \mathrm{mol}^{-1}\right)$ & $Ð\left(M_{\mathrm{w}} / M_{\mathrm{n}}\right)$ & $\begin{array}{l}\text { Percent ratio } \\
\text { (P2VP : PMMA) }\end{array}$ \\
\hline $\mathrm{P}\left(\mathrm{VP}_{3}-\mathrm{MMA}_{97}\right)$ & 23300 & 69200 & 59700 & 2.69 & $3: 97$ \\
\hline $\mathrm{P}\left(\mathrm{VP}_{10}-\mathrm{MMA}_{90}\right)$ & 40400 & 149000 & 221000 & 3.66 & $10: 90$ \\
\hline
\end{tabular}

${ }^{a}$ where $M_{\mathrm{n}}, M_{\mathrm{w}}, M_{\mathrm{p}}$ and $D$ are number average molar mass, weight average molar mass, molar mass at peak maximum, and polydispersity index respectively. Subscripts in sample coding represent the percent ratio of individual blocks. 
Instruments). The analyses were performed at a scattering angle of $90^{\circ}$ using disposable cuvette for zetasizer and dip cell cuvette for zeta potential studies, at $25{ }^{\circ} \mathrm{C}$.

The electrochemical experiments were performed on $\mathrm{CHI}-$ 600 series electrochemical analyzer using CHI-600C software. Three electrode assembly (from $\mathrm{CH}$ Instruments, Inc.) along with an electrochemical cell with Teflon cap having five taper holes, was used to record CVs. Working, reference and counter electrodes supplied by $\mathrm{CH}$ Instruments Inc. were fitted in these three holes prior to scan. Glassy carbon electrode (GCE; CHI104) with an area of $0.070 \mathrm{~cm}^{2}$ was employed. Modified GCE (modification protocol discussed in later Section 2.3.2) was used in combination with $\mathrm{Ag} / \mathrm{AgCl}$ (CHI111) and $\mathrm{Ag} / \mathrm{Ag}^{+}$(CHI112) as a reference electrode in aqueous and non-aqueous media, respectively, for detection of nicotine. Platinum wire (CHI115) was used as a counter electrode.

\subsection{Methods}

2.3.1. Preparation of $\mathbf{P}(2 \mathrm{VP}-\mathrm{MMA})$-AuNPs. Synthesis of $\mathrm{P}$ (2VP-MMA)-AuNPs was accomplished using a two-phase one pot system consisting of toluene and methanol (90:10), Fig. 1. Polymers form spherical micelles in toluene where polar poly(2vinylpyridine) (P2VP) segment makes the core while comparatively non-polar poly(methyl methacrylate) (PMMA) segment extends outward making shell. $1.0 \mathrm{~mL}(0.1 \mathrm{mM})$ aliquot of $\mathrm{P}$ (2VP-MMA) solution was added into $20 \mathrm{~mL}(0.25 \mathrm{mM})$ solution of $\mathrm{HAuCl}_{4} \cdot 3 \mathrm{H}_{2} \mathrm{O}$. The resulting solution was subsequently stirred for $30 \mathrm{~min}$, allowing the $\left[\mathrm{AuCl}_{4}\right]^{-1}$ to diffuse into the core of the micelles and making a complex with the pyridine groups of P2VP. $0.1 \mathrm{~mL}$ of $16 \mathrm{mM} \mathrm{NaBH}_{4}$ solution were added into the reaction mixture that reduce the $\mathrm{Au}(\mathrm{III})$ into $\mathrm{Au}(0) .{ }^{42}$ The appearance of pink color is the indication of formation of gold nanoparticles.

2.3.2. Electrochemical studies. GCE was modified with P(2VP-MMA)-AuNPs for electrochemical detection of nicotine. Modification of GCE was carried out by adopting a simple drop cast procedure. This was done by adding 1-2 drops of $\mathrm{P}(2 \mathrm{VP}-$ MMA)-AuNPs on surface of GCE and place it in upward position to air dry for 7-10 min. After complete drying, modified GCE was used as a working electrode connected with reference and counter electrode. Renewing surface of GCE is a staple part of this electrochemical study. Hence, surface of working electrode was renewed by polishing it with alumina (mesh size 0.3 micron) followed by sonication in acetone followed by distilled water for $5 \mathrm{~min}$, prior to modification.

A blank test solution was prepared by taking $5.0 \mathrm{~mL}$ of $0.1 \mathrm{M}$ solution of SE (KCl or TBAP) in electrochemical cell for voltammetric titration. This solution was then titrated by stepwise addition of specific volume $(\mu \mathrm{L})$ of freshly prepared $0.1-0.2 \mathrm{M}$ nicotine to maintain the minimum concentration and after each addition a voltammogram was recorded. All voltammetric measurements were referred to $\mathrm{Ag} / \mathrm{AgCl}$ and/or $\mathrm{Ag} / \mathrm{Ag}^{+}$with the scan rate of $0.1 \mathrm{~V} \mathrm{~s}^{-1}$. For non-aqueous system, silver-silver ion $\left(\mathrm{Ag} / \mathrm{Ag}^{+}\right)$electrode was used with freshly prepared $5.0 \mathrm{mM}$ solution of $\mathrm{AgNO}_{3}$ and $0.1 \mathrm{M}$ tetra- $n$-butyl ammonium perchlorate in acetonitrile.

Voltammetric (oxidative) wave of nicotine appears at positive potential, though an attempt of degassing the test solution by

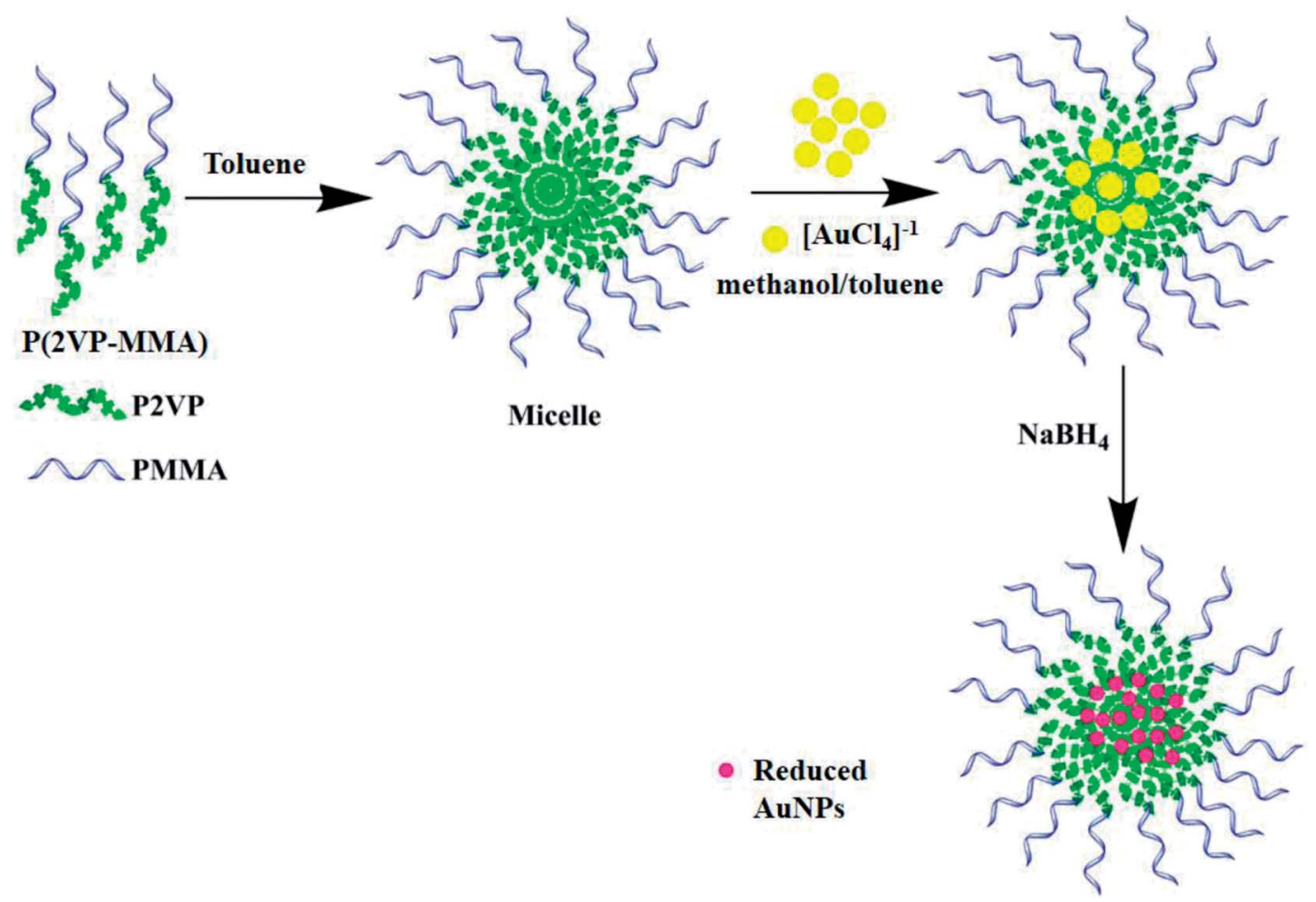

Fig. 1 Schematic illustration of the reduction process of $\mathrm{Au}($ (II) particles in the presence of a stabilizing block copolymer $\mathrm{P}(2 \mathrm{VP}-\mathrm{MMA})$ using $\mathrm{NaBH}_{4}$ as reducing agent. 
bubbling high purity argon gas is to be an optional. Scanning potential (positively) from 0 to $+1.4 \mathrm{~V}$ and subsequently reversing it back remained as a usual practice throughout this study.

\section{Results and discussion}

\subsection{Characterization of P(2VP-MMA)-AuNPs}

Reduction of gold ions into gold nanoparticles is indicated by conversion of yellow reaction mixture to pink, also confirmed by measuring UV-Vis spectra of the solution that showed an absorption band at $525 \mathrm{~nm}$ (Fig. 2). Typically, gold nanoparticles have an characteristics absorption band between 500 and $600 \mathrm{~nm} \cdot .^{43}$ It was observed that block copolymer having individual block ratio of $3: 97$ fabricated more uniform nanoparticles, indicated by high intensity of UV-Vis absorption band.
We have recently shown that the stability of AuNPs increases with the molar mass of stabilizing P2VP hompolymers. ${ }^{41}$ On the same lines, effect of the molar mass of P2VP block in the block copolymer on the stability of NPs is expected. The spherical shape and localized nature of $\mathrm{P}$ (2VP-MMA)-AuNPs was confirmed by AFM. Moreover, the block copolymers make micelles with P2VP core shielded by PMMA shell, Fig. 3.

Furthermore, the particles size and distribution of AuNPs depends upon both the total molar mass and molar mass of P2VP block. The average size and size distribution profiles of $\mathrm{P}\left(2 \mathrm{VP}_{3}-\mathrm{MMA}_{97}\right)$-AuNPs, $\mathrm{P}\left(2 \mathrm{VP}_{15}-\mathrm{MMA}_{85}\right)$-AuNPs, and $\mathrm{P}\left(2 \mathrm{VP}_{10^{-}}\right.$ $\mathrm{MMA}_{90}$ )-AuNPs as analyzed by zetasizer are shown in Fig. 4 . The $\mathrm{P}\left(2 \mathrm{VP}_{3}-\mathrm{MMA}_{97}\right)$ and $\mathrm{P}\left(2 \mathrm{VP}_{15}-\mathrm{MMA}_{85}\right)$ have similar total molar mass, however, the length of $\mathrm{P} 2 \mathrm{VP}$ block of latter is higher. The average diameter of the $\mathrm{P}\left(2 \mathrm{VP}_{3}-\mathrm{MMA}_{97}\right)$-AuNPs was $31.80 \pm$ $20.01 \mathrm{~nm}$ compared to $71.83 \pm 19.26 \mathrm{~nm}$ for $\mathrm{P}\left(2 \mathrm{VP}_{15}-\mathrm{MMA}_{85}\right)$ AuNPs. On the other hand, the average diameter of $\mathrm{P}\left(2 \mathrm{VP}_{10^{-}}\right.$

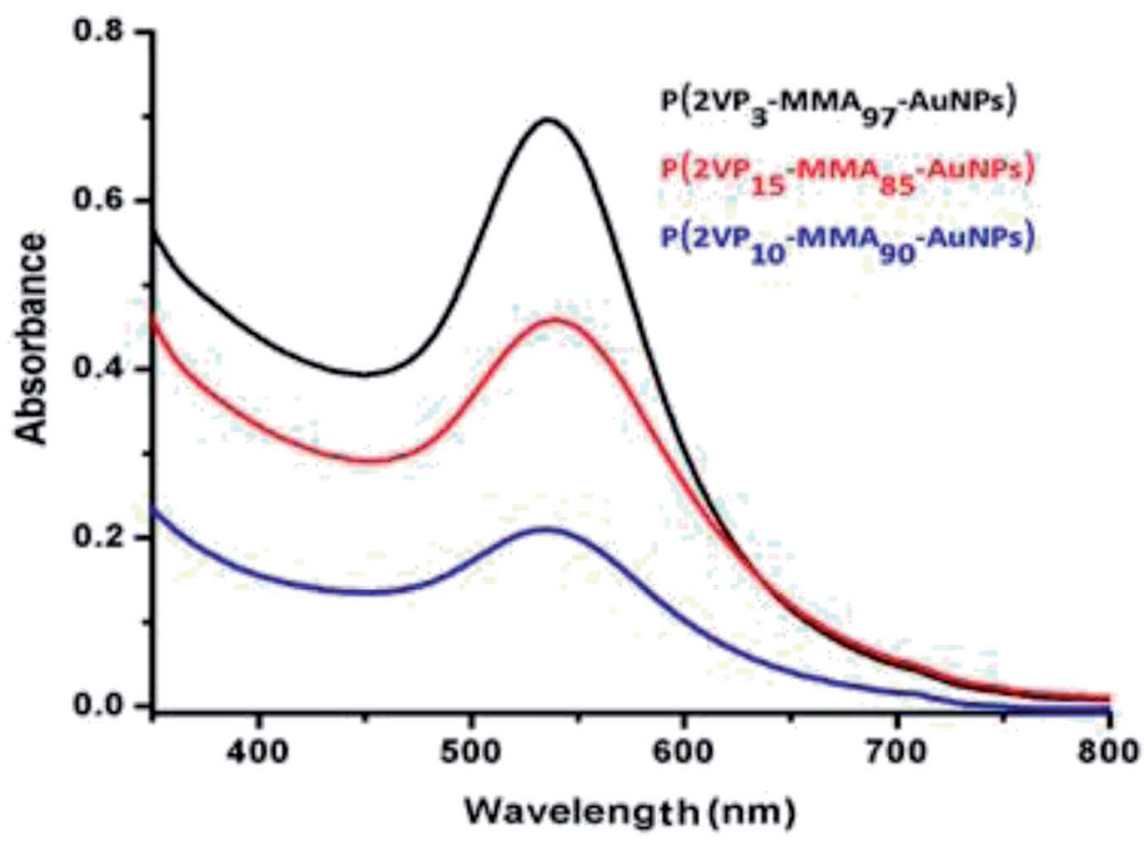

Fig. 2 UV-Vis spectra of P(2VP-MMA)-AuNPs stabilized by different block copolymers varying in total molar mass and chemical composition.
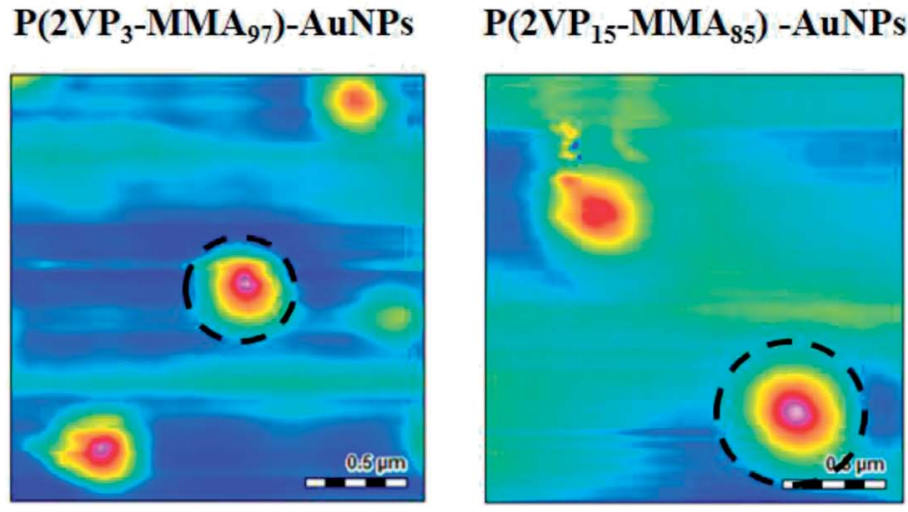
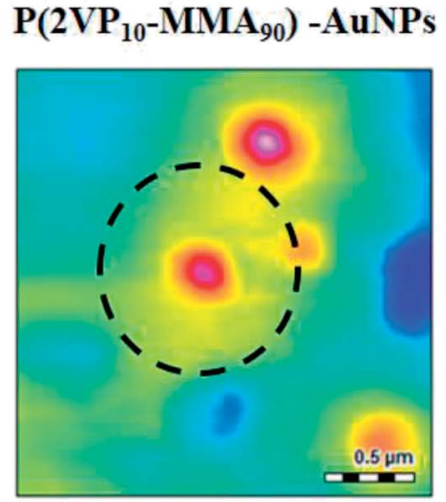

Fig. 3 AFM images of P(2VP-MMA)-AuNPs. 

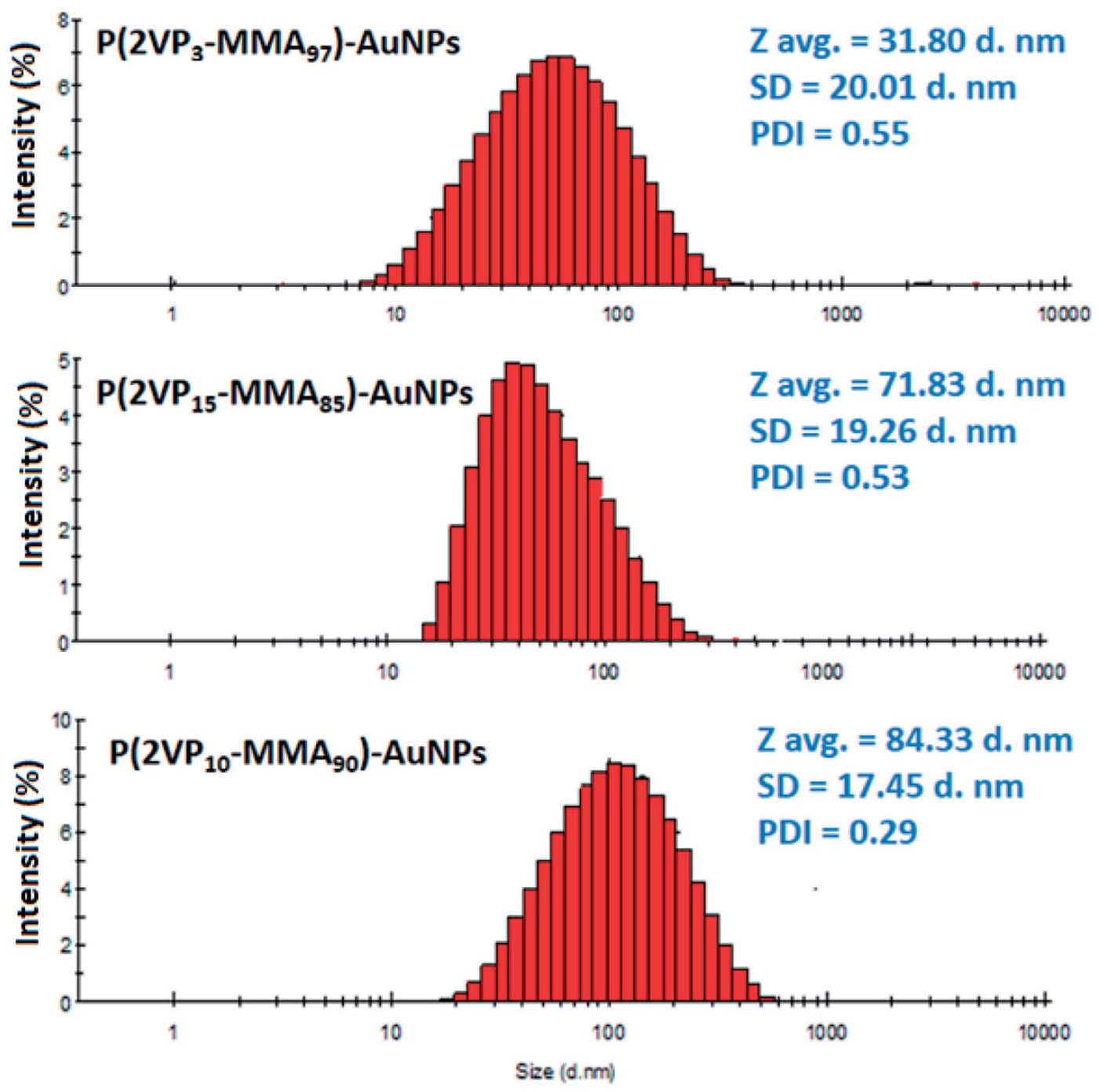

Fig. 4 Size distribution by intensity of $P\left(2 V P_{3}-M M A_{97}\right)-A u N P s, P\left(2 V P_{15}-M M A_{85}\right)-A u N P s$, and $P\left(2 V P_{10}-M M A_{90}\right)-A u N P s$.

$\left.\mathrm{MMA}_{90}\right)$-AuNPs $(84.33 \pm 17.45 \mathrm{~d} . \mathrm{nm})$ was even higher than the $\mathrm{P}\left(2 \mathrm{VP}_{15}-\mathrm{MMA}_{85}\right)$-AuNPs $(71.83 \pm 19.26 \mathrm{~nm})$. In this case, the length of P2VP block was similar; however, total molar mass of the latter was lower. Therefore, we can conclude that the size of the AuNPs prepared by P(2VP-MMA) increases with the molar mass of individual P2VP block as well as with the total molar mass of the block copolymer.

The formation of P(2VP-MMA)-AuNPs was attributed to the coordination between lone pair of electrons of pyridine nitrogen in the polymer with gold particles. Comparison of FTIR spectra of P(2VP-MMA), P(2VP-MMA)-AuNPs and AuNPs supports the assumption (Fig. 5). The absorption bands at $1150 \mathrm{~cm}^{-1}$ and $1247 \mathrm{~cm}^{-1}$ are attributed to the $\mathrm{C}-\mathrm{O}-\mathrm{C}$ stretching vibration, and two bands at $1388 \mathrm{~cm}^{-1}$ and $752 \mathrm{~cm}^{-1}$ to the $\alpha$-methyl group vibrations in PMMA. The bands at 1065, 985 and $843 \mathrm{~cm}^{-1}$ are the characteristic peaks for vibration of PMMA. The $1732 \mathrm{~cm}^{-1}$ band shows the presence of the acrylate carboxyl group. The band at $1444 \mathrm{~cm}^{-1}$ can be assigned to the bending vibration of $\mathrm{C}-\mathrm{H}$ bonds of the $-\mathrm{CH}_{3}$ group and the two bands at $3002 \mathrm{~cm}^{-1}$ and $2952 \mathrm{~cm}^{-1}$ to $\mathrm{C}-\mathrm{H}$ bond stretching vibrations of the $-\mathrm{CH}_{3}$ and $-\mathrm{CH}_{2}-$ groups, respectively. Furthermore, two weak absorption bands at $3442 \mathrm{~cm}^{-1}$ and $1641 \mathrm{~cm}^{-1}$ can be assigned to the stretching and bending vibrations of $-\mathrm{OH}$ group of absorbed moisture, respectively. The characteristic $-\mathrm{C}=\mathrm{N}$ pyridine ring vibrations appear at $1595 \mathrm{~cm}^{-1}$. The disappearance of $-\mathrm{C}=\mathrm{N}$ band and the appearance of $1650 \mathrm{~cm}^{-1}$ band after loading of AuNPs confirms that P2VP block in the core of $\mathrm{P}(2 \mathrm{VP}-\mathrm{MMA})$ micelles is mainly responsible for the stabilization of AuNPs.

Zeta potential indicates the presence of positive charges on the surface of $\mathrm{P}(2 \mathrm{VP}-\mathrm{MMA})$-AuNPs. The zeta potential of $\mathrm{P}\left(2 \mathrm{VP}_{3}\right.$ $\left.\mathrm{MMA}_{97}\right)$-AuNPs, $\mathrm{P}\left(2 \mathrm{VP}_{15}-\mathrm{MMA}_{85}\right)$-AuNPs, and $\mathrm{P}\left(2 \mathrm{VP}_{10}-\mathrm{MMA}_{90}\right)$ AuNPs are presented in Fig. 6 . The surfaces charges on $\mathrm{P}\left(2 \mathrm{VP}_{3}\right.$ $\left.\mathrm{MMA}_{97}\right)$-AuNPs, $\mathrm{P}\left(2 \mathrm{VP}_{15}-\mathrm{MMA}_{85}\right)$-AuNPs, and $\mathrm{P}\left(2 \mathrm{VP}_{10}-\mathrm{MMA}_{90}\right)$ AuNPs corresponds to zeta potential of 23.5, 0.0276 and $0.0196 \mathrm{mV}$, respectively. More positive charge on $\mathrm{P}\left(2 \mathrm{VP}_{3}\right.$ $\mathrm{MMA}_{97}$ )-AuNPs indicates their better stability compared to other two samples. The reason might be better interaction of P2VP with AuNPs because of higher solubility of $\mathrm{P}\left(2 \mathrm{VP}_{3}-\mathrm{MMA}_{97}\right)$ in toluene owing to its larger PMMA block. The positive charges 


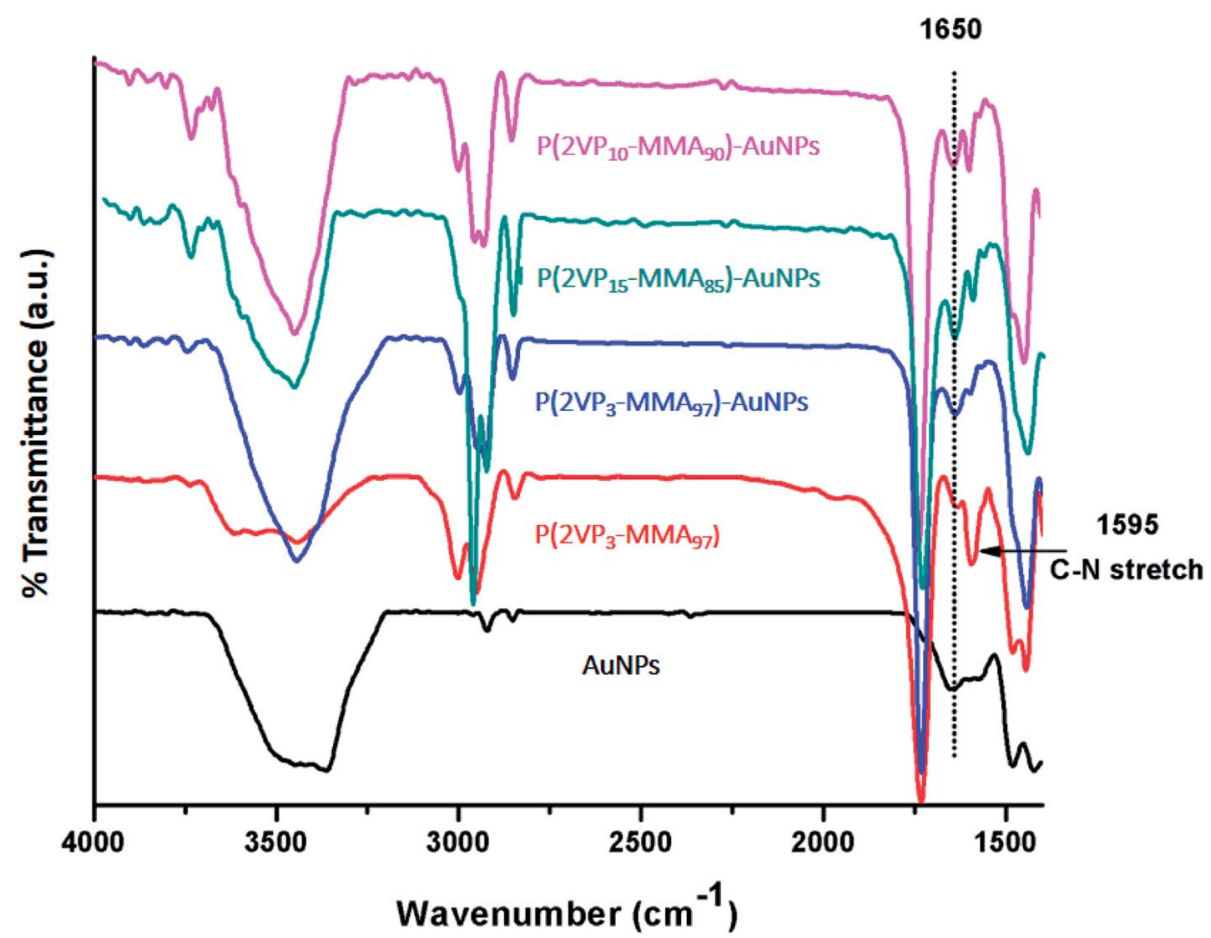

Fig. 5 Comparative FTIR spectra of P(2VP-MMA)-AuNPs, P(2VP-MMA) and AuNPs.
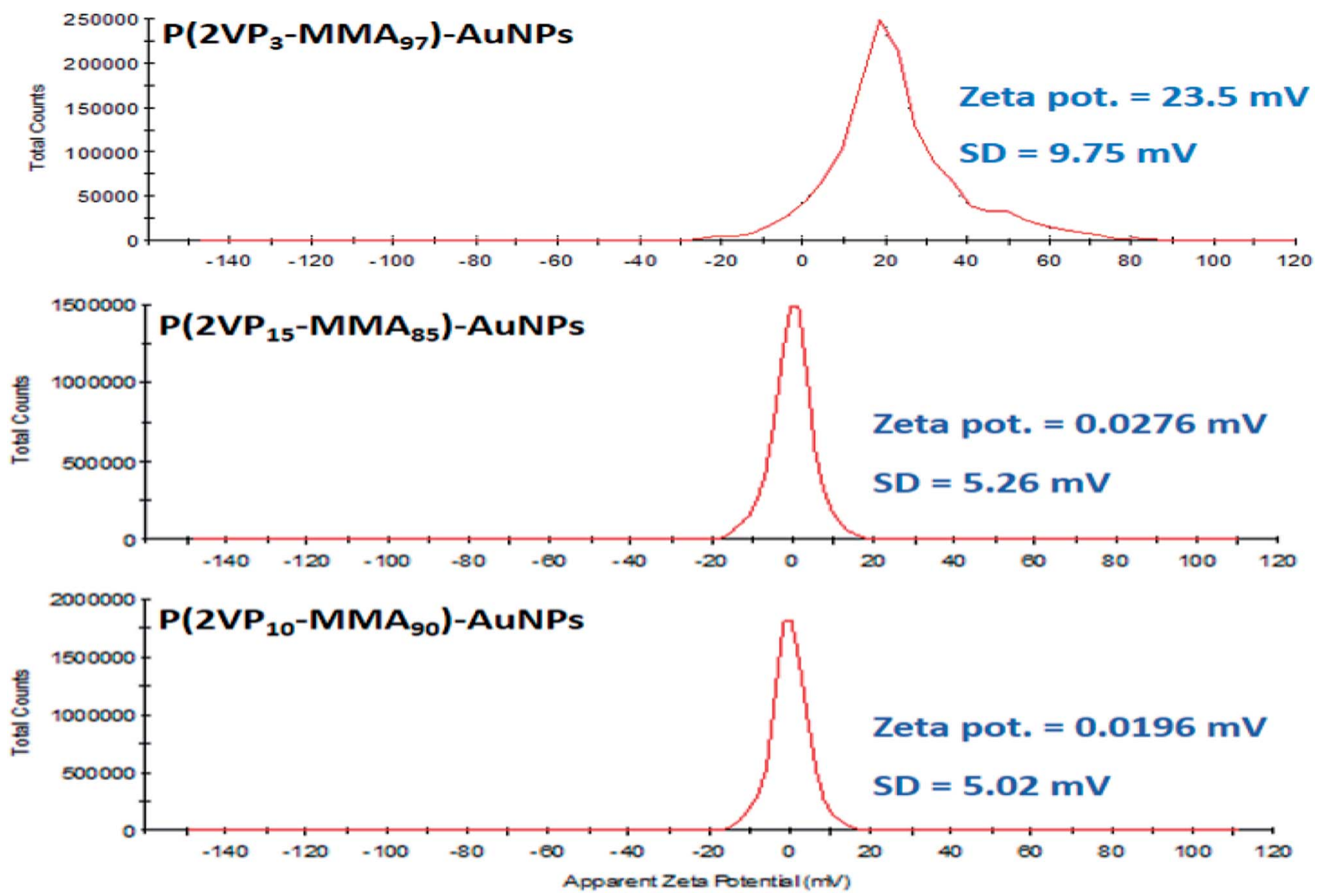

Fig. 6 Zeta potential distribution $\mathrm{P}\left(2 \mathrm{VP}_{3}-\mathrm{MMA}_{97}\right)-A u N P s, \mathrm{P}\left(2 \mathrm{VP}_{15}-\mathrm{MMA}_{85}\right)-A u N P s$, and $\mathrm{P}\left(2 \mathrm{VP}_{10}-\mathrm{MMA}_{90}\right)-A u N P s$. 
on the polymer surface make the P(2VP-MMA)-AuNPs electroactive in nature, that reacts with the basic nitrogen atoms in nicotine. This interaction allowed for employing the $\mathrm{P}\left(2 \mathrm{VP}_{3}\right.$ $\mathrm{MMA}_{97}$ )-AuNPs as novel electrochemical sensor for nicotine. $\mathrm{P}\left(2 \mathrm{VP}_{3}-\mathrm{MMA}_{97}\right)$-AuNPs seems to be more stable compared to other two polymer combinations with $\mathrm{Au}$ and have high surface charges, hence, might acts as a better sensor for nicotine. Therefore, $\mathrm{P}\left(2 \mathrm{VP}_{3}-\mathrm{MMA}_{97}\right)$-AuNPs are selected for further studies.

As a next step, the stability of the synthesized AuNPs as a function of storage time was monitored by UV-Vis spectroscopy and AFM analysis. The $\mathrm{P}\left(2 \mathrm{VP}_{3}-\mathrm{MMA}_{97}\right)$-AuNPs remained stable for fairly longer time at ambient temperature, Fig. S1ESI. $\dagger$ UV-Vis spectroscopy reveals the enhancement in the SPR signal with storage time up to two months, Fig. S1A-ESI. $\dagger$ However, SPR signal decreased after two months that indicates the agglomeration of the NPs into aggregates. These observations vis-à-vis stored AuNPs at different time interval were further confirmed by AFM analysis (see Fig. S1B-ESI $\dagger$ ).

Thermal stability of $\mathrm{P}\left(2 \mathrm{VP}_{3}-\mathrm{MMA}_{97}\right)$-AuNPs was evaluated by elevating temperature of specified polymer solution to $100{ }^{\circ} \mathrm{C}$ for 10 minutes and then cooling it to ambient temperature (25 $\left.{ }^{\circ} \mathrm{C}\right)$. UV-Vis spectrum of temperature treated sample showed an enhancement in absorption maxima $\left(A_{\max }\right)$ of SPR band which indicates relatively higher stability. At higher temperatures, solubility of polymers increases that provides larger functionalized area and promotes conversion of gold ions into gold nanoparticles thus enhancing the stability of AuNPs (Fig. S2ESI $\dagger) .{ }^{41}$

Generally, addition of electrolytes in NPs solution results in aggregation of nanoparticles. A thorough study was carried out to elucidate the effect of concentration of electrolytes $(0.001$ mM-5 $\mathrm{M} \mathrm{NaCl})$ on $\mathrm{P}\left(2 \mathrm{VP}_{3}-\mathrm{MMA}_{97}\right)$-AuNPs stability, monitored by UV-Vis spectroscopy. $\mathrm{P}\left(2 \mathrm{VP}_{3}-\mathrm{MMA}_{97}\right)$-AuNPs were stable over a wide range of concentration of sodium chloride, Fig. S3-ESI. $\dagger$

Effect of $\mathrm{pH}$ on the stability of $\mathrm{P}\left(2 \mathrm{VP}_{3}-\mathrm{MMA}_{97}\right)$-AuNPs was examined in a range of $2-12$ by monitoring the change in SPR band in UV-Vis spectrum, Fig. S4-ESI. $\uparrow$ The position and shape of the SPR band was not altered with variations in $\mathrm{pH}$ from 2 to 12 , confirming that aggregation and agglomeration is protected over a wide range of $\mathrm{pH}$. The enhancement in SPR band at higher $\mathrm{pH}$ might be due to formation of less reactive $[\mathrm{AuCl}(4-$ $\left.n)(\mathrm{OH})_{n}\right]^{-}$complex by the reaction of $\left[\mathrm{AuCl}_{4}\right]^{-}$with $\mathrm{OH}^{-}$ions of sodium hydroxide, where $n$ increases with increase in the pH. ${ }^{44-46}$

\subsection{Cyclic voltammetric detection of nicotine using $\mathbf{P}\left(2 \mathrm{VP}_{3^{-}}\right.$ MMA $_{97}$ )-AuNPs-GCE}

Cyclic voltammetry (CV) was used to explore the electrochemical sensing application of the prepared nanocomposites $\mathrm{P}\left(2 \mathrm{VP}_{3}\right.$ $\left.\mathrm{MMA}_{97}\right)$-AuNPs, $\mathrm{P}\left(2 \mathrm{VP}_{15}-\mathrm{MMA}_{85}\right)$-AuNPs and $\mathrm{P}\left(2 \mathrm{VP}_{10}-\mathrm{MMA}_{90}\right)$ AuNPs for the detection of nicotine. In this context, glassy carbon electrode (GCE) was modified with above-mentioned NPs composites (AuNPs stabilized by polymer) for its application as a redox probe. Nevertheless, this work primarily emphasizes on $\mathrm{P}\left(2 \mathrm{VP}_{3}-\mathrm{MMA}_{97}\right)$-AuNPs. The reason for emphasizing specifically on $\mathrm{P}\left(2 \mathrm{VP}_{3}-\mathrm{MMA}_{97}\right)$-AuNPs is a welldefined oxidative wave of nicotine with significant peak intensities (current response) via $\left[\mathrm{P}\left(2 \mathrm{VP}_{3}-\mathrm{MMA}_{97}\right)\right.$-AuNPs]-GCE compared to other composites (Fig. 7) and better stability of these NPs compared to other two samples as indicated by zeta potentials (Fig. 6). The major part of this work was performed in non-aqueous inert environment. Hence, the most likely process of detection is single electron transfer that occurs between GCE and nicotine anodically. More techniques such as DPV or digital simulation are required for detailed mechanism study. Moreover, the focus of current study is enhancement in the electrochemical response of nicotine on NPs-fabricated GCE compared to bare GCE using cyclic voltammetry.

It could infer that the electron conductivity (or tunneling) through $\left[\mathrm{P}\left(2 \mathrm{VP}_{3}-\mathrm{MMA}_{97}\right)\right.$-AuNPs]-GCE is higher, compared to the other composites modified GCE probes. Hence, the modification of GCE offers an enhanced electrochemical area of the electrode which facilitates the electron transfer kinetic between the surface of $\mathrm{P}\left(2 \mathrm{VP}_{3}-\mathrm{MMA}_{97}\right)$-AuNPs-GCE and nicotine. The appearance of an irreversible peak in the anodic region at voltammetric time scale as a result of electro-oxidation of nicotine is an established fact. By scanning potential anodically, 0 to $+1.4 \mathrm{~V}$, no voltammetric peak/wave appeared at the bare GCE in the absence of nicotine (both in aqueous and non-aqueous medium), Fig. S5-ESI. $\dagger$ Furthermore, a completely irreversible peak appeared at $+1.154 \mathrm{~V}$ at NPs composite-modified GCE in the absence of nicotine while acetonitrile was used as a solvent, Fig. S6-ESI. $\dagger$

This redox peak seems to be a characteristic peak of the composite, $\mathrm{P}\left(2 \mathrm{VP}_{3}-\mathrm{MMA}_{97}\right)$-AuNPs sensor, applied for GCE fabrication. However, an ill-defined wave or a slight hump (of NPs composite) appeared at $+1.02 \mathrm{~V}$ in aqueous medium at $\mathrm{pH}$ $=6.8 \pm 0.1$ (Figure not shown). The electro inactive nature of polymer, $\mathrm{P}\left(2 \mathrm{VP}_{3}-\mathrm{MMA}_{97}\right)$ was confirmed by casting pure $\mathrm{P}\left(2 \mathrm{VP}_{3}\right.$ $\mathrm{MMA}_{97}$ ) on GCE surface in acetonitrile, where no peak appeared in anodic region, Fig. S7-ESI. $\dagger$

The observations suggest that the peak appeared at $+1.154 \mathrm{~V}$ is more likely due to $\mathrm{P}\left(2 \mathrm{VP}_{3}-\mathrm{MMA}_{97}\right)$-AuNPs. Unstable AuNPs (in absence of polymer) does not show any appreciable electrochemical response for nicotine. Scanning potential in negative region of deoxygenated solution (of $0.1 \mathrm{M} \mathrm{TBAP} / \mathrm{KCl}$ ) was also attempted for the peak referred to sensing; no peak or hump was observed.

Nicotine is an alkaloid, more soluble in polar-aprotic solvents compared to aqueous medium. The difference could clearly be observed in the voltammograms depicted in Fig. 8A and $\mathrm{B}$. The bare GCE responds to nicotine concentration higher than $0.2 \mathrm{M}$ in acetonitrile, Fig. 8A. Conversely, only slight or illdefined humps appeared in aqueous medium (see Fig. 8B). Nonetheless, this study significantly focuses on non-aqueous medium i.e. acetonitrile. GCE modified with $\mathrm{P}\left(2 \mathrm{VP}_{3}-\mathrm{MMA}_{97}\right)$ AuNPs was tested for electrochemical response against nicotine. Thereafter, the sensitivity of P(2VP-MMA)-AuNPs-GCE probe as a function of nicotine concentration in acetonitrile was investigated. The current density increased with increase in the concentration of nicotine as shown in Fig. 9. Well-defined concentration dependent cyclic voltammetric peaks appeared 


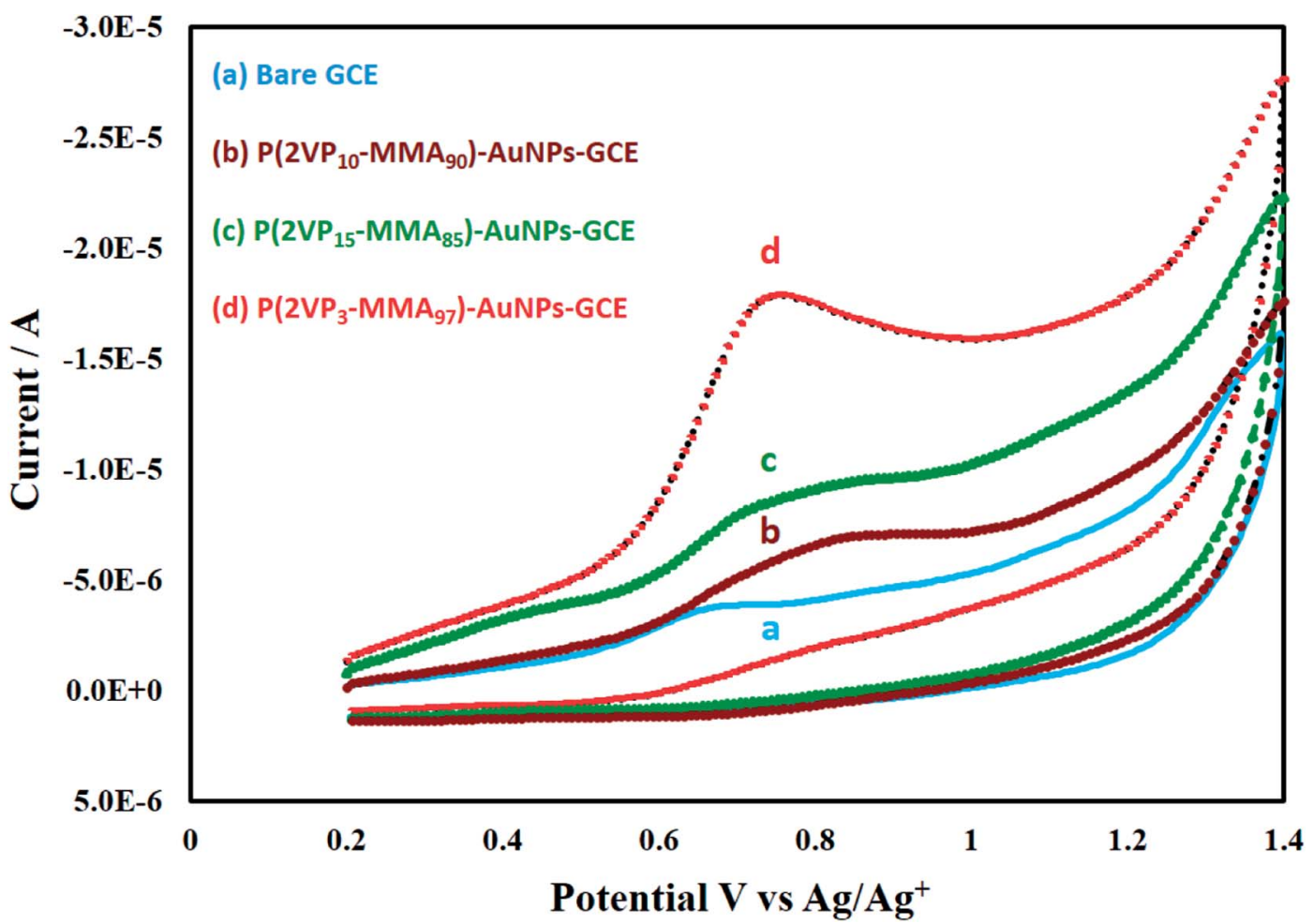

Fig. 7 Voltammetric response of nicotine on (a) bare GCE; (b) $P\left(2 V P_{10}-M M A_{90}\right)-A u N P s$, (c) $P\left(2 V P_{15}-M M A_{85}\right)-A u N P s$, and (d) $P\left(2 V P_{3}-M M A_{97}\right)-$ AuNPs fabricated GCE.

on modified GCE. The detection limit of the modified GCE probe is enhanced, down to $0.1 \mathrm{mM}$ nicotine concentration.

Comparative view of electrochemical response of nicotine on bare GCE, $\mathrm{P}\left(2 \mathrm{VP}_{3}-\mathrm{MMA}_{97}\right)-\mathrm{GCE}, \mathrm{P}\left(2 \mathrm{VP}_{3}-\mathrm{MMA}_{97}\right)$-AuNPs-GCE is demonstrated in Fig. 10.

Highest signal for $0.4 \mathrm{mM}$ nicotine is obtained with $\mathrm{P}\left(2 \mathrm{VP}_{3}\right.$ $\left.\mathrm{MMA}_{97}\right)$-AuNPs-GCE. The $\mathrm{P}\left(2 \mathrm{VP}_{3}-\mathrm{MMA}_{97}\right)$-GCE does not show any response while response of bare GCE is considerably less compared to $\mathrm{P}\left(2 \mathrm{VP}_{3}-\mathrm{MMA}_{97}\right)$-AuNPs-GCE. Fig. 11 shows the electrochemical response of $0.1 \mathrm{mM}$ nicotine on bare GCE and $\mathrm{P}\left(2 \mathrm{VP}_{3}-\mathrm{MMA}_{97}\right)$-AuNPs-GCE, in acetonitrile.
As can be noticed, bare GCE was not able to detect nicotine ( $0.1 \mathrm{mM})$ compared to an effective response shown by $\mathrm{P}\left(2 \mathrm{VP}_{3}\right.$ $\mathrm{MMA}_{97}$ )-AuNPs-GCE. Hence, the detection limit and efficiency of modified GCE is improved considerably compared to bare GCE for nicotine. The comparison of peak current as a function of nicotine concentration is demonstrated in Fig. 12.

The peak current increases with increasing concentration of nicotine linearly with a high statistical correlation $R^{2}$ value, 0.986 . The stability and reproducibility of $\mathrm{P}\left(2 \mathrm{VP}_{3}-\mathrm{MMA}_{97}\right)$ AuNPs-GCE probe against nicotine was also investigated at different time intervals. For this particular study, the $\mathrm{P}\left(2 \mathrm{VP}_{3}\right.$ -
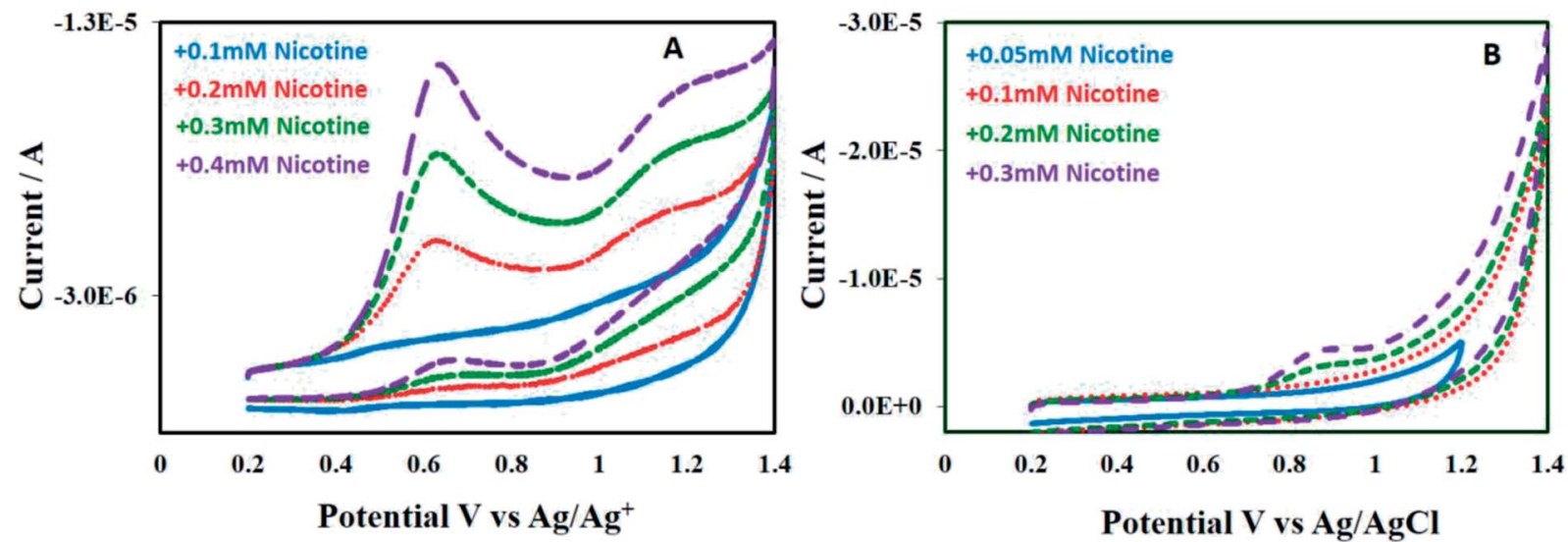

Fig. 8 Cyclic voltammograms of nicotine with various concentrations ranging from $0.05 \mathrm{mM}$ to $0.4 \mathrm{mM}$ on bare GCE in (A) acetonitrile; (B) distilled deionized water. 


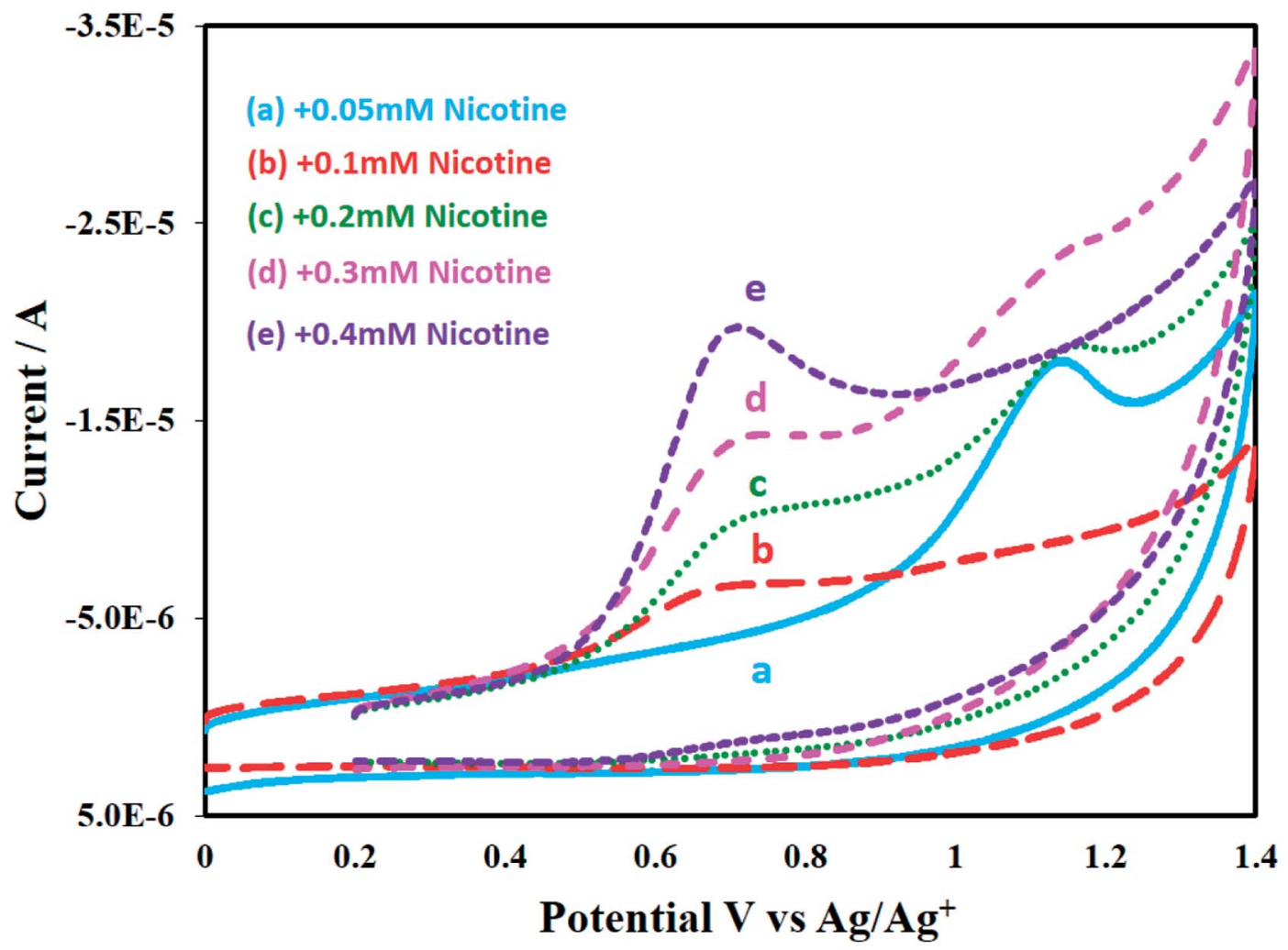

Fig. 9 Effect of various concentrations (from $0.05 \mathrm{mM}-0.4 \mathrm{mM}$ ) of nicotine on $\mathrm{P}\left(2 \mathrm{VP}_{3}-\mathrm{MM} \mathrm{A}_{97}\right.$ )-AuNPs-GCE in acetonitrile.

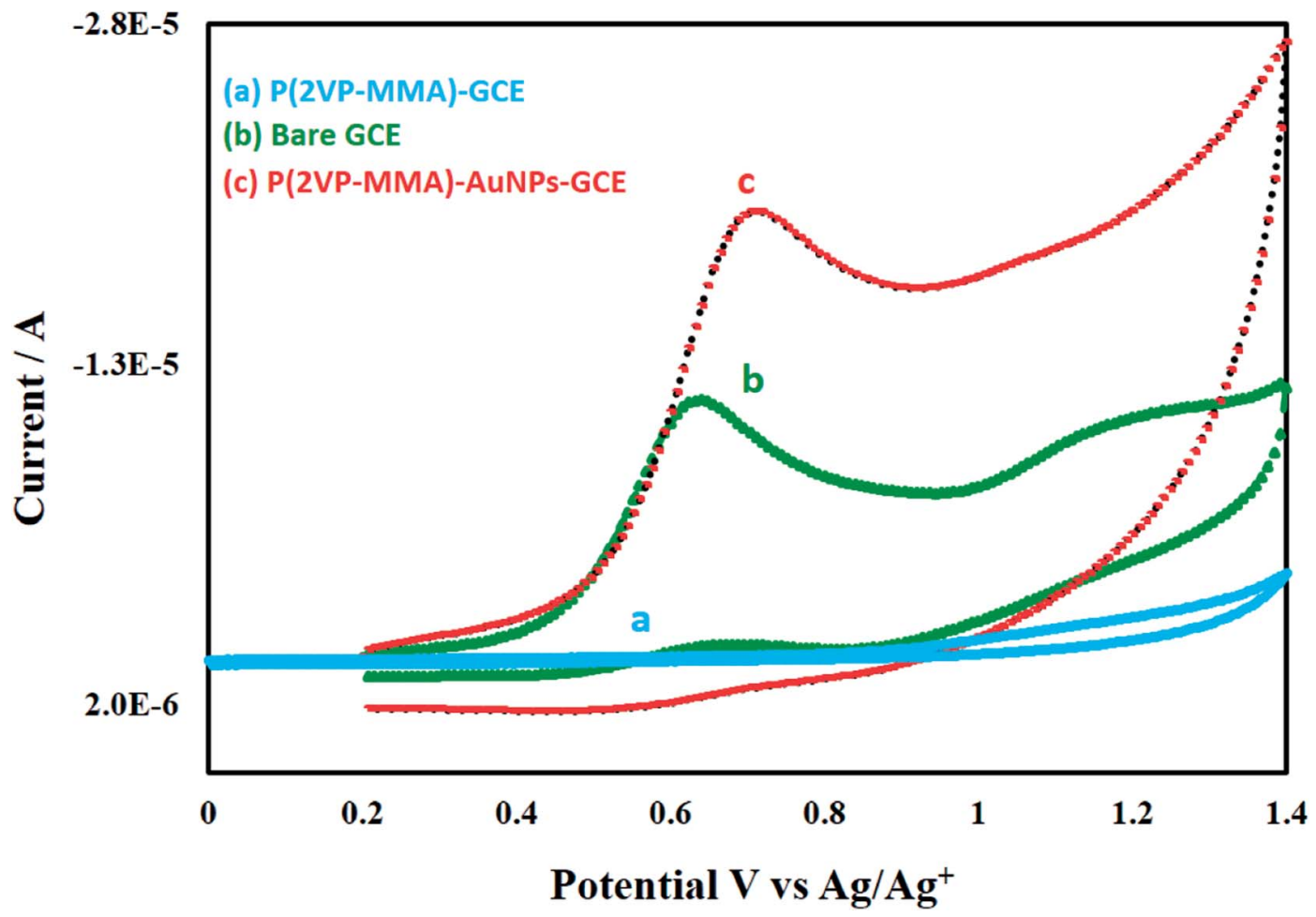

Fig. 10 Comparison of cyclic voltammograms of $0.4 \mathrm{mM}$ nicotine on (a) $\mathrm{P}\left(2 \mathrm{VP}_{3}-\mathrm{MMA}_{97}\right)-\mathrm{GCE}$ (b) bare $\mathrm{GCE}$ and (c) $\mathrm{P}\left(2 \mathrm{VP} \mathrm{P}_{3}-\mathrm{MMA}_{97}\right)-\mathrm{AuNPs}_{3}$ GCE-sensor in acetonitrile. 


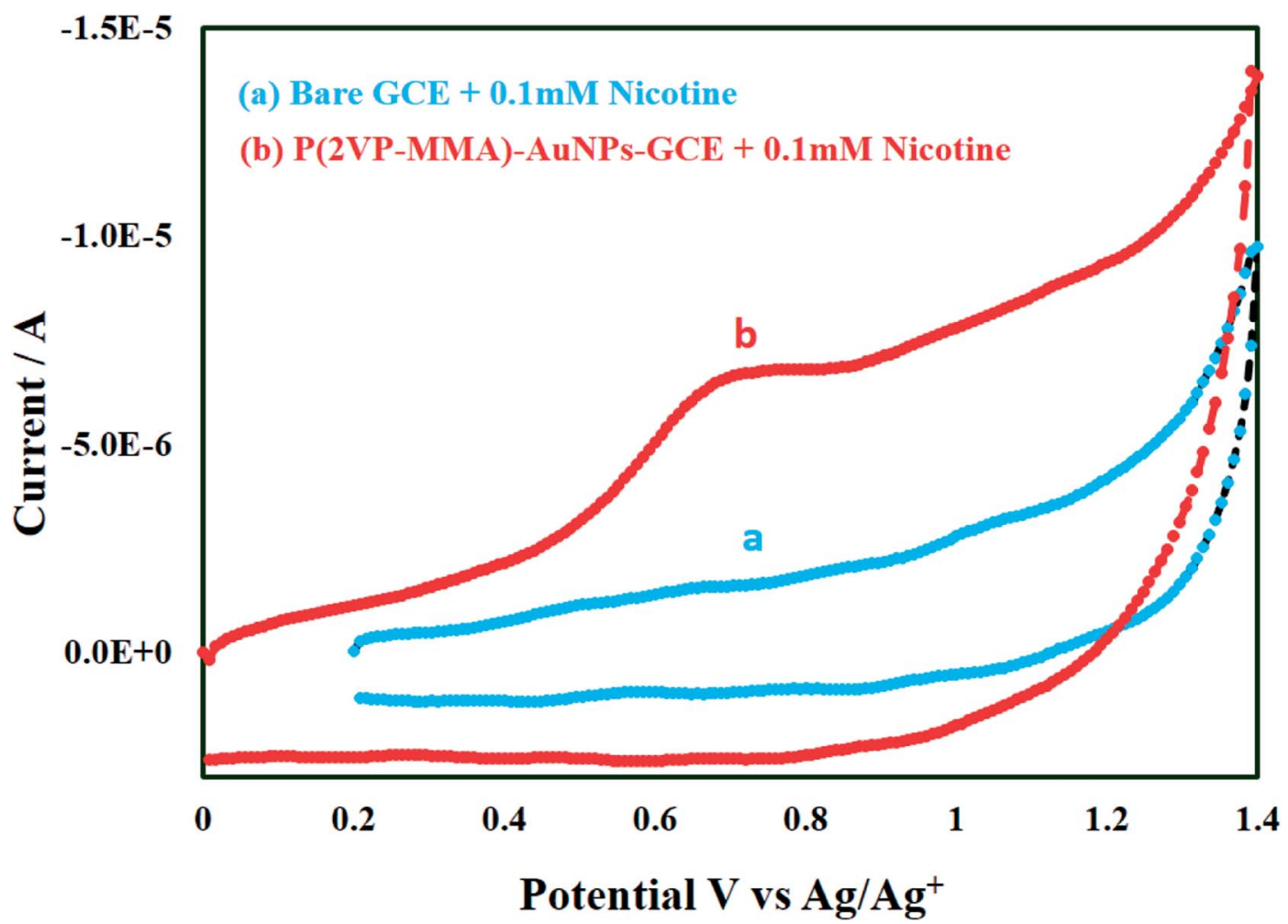

Fig. 11 Comparison of cyclic voltammograms of $0.1 \mathrm{mM}$ nicotine on (a) bare $G C E$ and (b) $P\left(2 V P_{3}-M M A_{97}\right)$-AuNPs-GCE in acetonitrile.

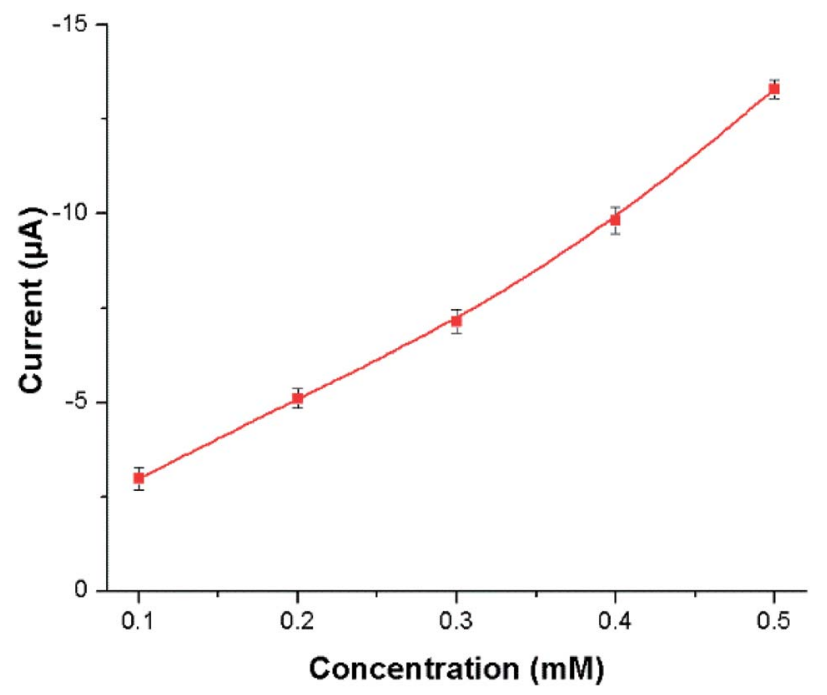

Fig. 12 Plot of oxidative peak current as a function of concentration of nicotine $(0.1 \mathrm{mM}-0.5 \mathrm{mM})$.

$\mathrm{MMA}_{97}$ )-AuNPs were refrigerated (below $5{ }^{\circ} \mathrm{C}$ ). The sensor performance of $\mathrm{P}\left(2 \mathrm{VP}_{3}-\mathrm{MMA}_{97}\right)$-AuNPs-GCE probe for nicotine detection was not affected after four weeks of storage.

\section{Conclusion}

In this study, a novel $\mathrm{P}\left(2 \mathrm{VP}_{3}-\mathrm{MMA}_{97}\right)$-AuNPs-GCE based electrochemical probe is reported for rapid quantitative assay of nicotine. Stability and homogeneous nature of $\mathrm{P}\left(2 \mathrm{VP}_{3}-\mathrm{MMA}_{97}\right)-$
AuNPs was confirmed by UV-Vis, FTIR, AFM, and zetasizer. The sensitivity of bare GCE is significantly enhanced by coating with $\mathrm{P}\left(2 \mathrm{VP}_{3}-\mathrm{MMA}_{97}\right)$-AuNPs. A well-developed voltammetric peak was appeared at $+0.66 \mathrm{~V}$ (versus $\mathrm{Ag} / \mathrm{Ag}^{+}$), in acetonitrile for determination of nicotine in the concentration range of 0.1$0.4 \mathrm{mM}$ with a detection limit of $0.1 \mathrm{mM}$. The $\mathrm{P}\left(2 \mathrm{VP}_{3}-\mathrm{MMA}_{97}\right)-$ AuNPs-GCE is more sensitive towards nicotine, the electrochemical response obtained by $\mathrm{P}\left(2 \mathrm{VP}_{3}-\mathrm{MMA}_{97}\right)$-AuNPs-GCE is enhanced by an enhancement factor of $\sim 2$ compared to bare GCE. Simple, facile, low cost synthesis and high stability of $\mathrm{P}\left(2 \mathrm{VP}_{3}-\mathrm{MMA}_{97}\right)$-AuNPs-GCE make it a valuable choice for routine laboratory testing.

\section{Conflicts of interest}

Authors declare no conflict of interest.

\section{References}

1 D. Selmar, A. Radwan and M. Nowak, J. Environ Anal. Toxicol., 2015, 5, 287.

2 T. C. Sparks and R. Nauen, Pestic. Biochem. Physiol., 2015, 121, 122-128.

3 S. Thesleff, Acta Physiol. Scand., 1955, 34, 218-231.

4 A. Armitage and G. Hall, Nature, 1967, 214, 977-979.

5 A. V. Hill, J. Physiol., 1909, 39, 361-373.

6 A. J. Alberg, Drugs Today, 2008, 44, 895-904.

7 D. Yildiz, Toxicon, 2004, 43, 619-632.

8 J. M. Cameron, D. N. Howell, J. R. White, D. M. Andrenyak, M. E. Layton and J. M. Roll, Tob. Control, 2014, 23, 77-78. 
9 M. L. Goniewicz, T. Kuma, M. Gawron, J. Knysak and L. Kosmider, Nicotine Tob. Res., 2013, 15, 158-166.

10 R. A. Davis, J. Chromatogr. Sci., 1986, 24, 134-141.

11 G. N. Mahoney and W. Al-Delaimy, J. Chromatogr. B: Biomed. Sci. Appl., 2001, 753, 179-187.

12 C. Wu, W. F. Siems, J. H. H. Hill and R. M. Hannan, J. Chromatogr. A, 1998, 811, 157-161.

13 C. Patrianakos and D. Hoffmann, J. Anal. Toxicol., 1979, 3, 150-154.

14 K. T. McManus, J. D. deBethizy, D. A. Garteiz, G. A. Kyerematen and E. S. Vesell, J. Chromatogr. Sci., 1990, 28, 510-516.

15 J. M. Gonzalez, M. W. Foley, N. M. Bieber, P. A. Bourdelle and R. S. Niedbala, Anal. Bioanal. Chem., 2011, 400, 3655-3664.

16 E. V. J. Puhakainen, R. D. Barlow and J. T. Salonen, Clin. Chim. Acta, 1987, 170, 255-262.

17 F.-M. Matysik, J. Chromatogr. A, 1999, 853, 27-34.

18 M. B. Mamián-López and R. J. Poppi, Anal. Chim. Acta, 2013, 760, 53-59.

19 Ľ. Švorc, D. M. Stanković and K. Kalcher, Diamond Relat. Mater., 2014, 42, 1-7.

20 H. B. Suffredini, M. C. Santos, D. De Souza, L. Codognoto, P. Homem-de-Mello, K. M. Honório, A. Da Silva, S. A. Machado and L. A. Avaca, Anal. Lett., 2005, 38, 15871599.

21 P. T. Kissinger and W. R. Heineman, J. Chem. Educ., 1983, 60, 702.

22 Electroanalytical Methods - Guide to Experiments and Applications, ed. F. Scholz, Springer-Verlag, Berlin, Heidelberg, 2010.

23 J. Heinze, Angew. Chem., Int. Ed., 1984, 23, 831-847.

24 L. Highton, R. O. Kadara, N. Jenkinson, B. Logan Riehl and C. E. Banks, Electroanalysis, 2009, 21, 2387-2389.

25 M. J. Sims, N. V. Rees, E. J. F. Dickinson and R. G. Compton, Sens. Actuators, B, 2010, 144, 153-158.

26 T. W. B. Lo, L. Aldous and R. G. Compton, Sens. Actuators, B, 2012, 162, 361-368.

27 Y. Jing, X. Yuan, Q. Yuan, K. He, Y. Liu, P. Lu, H. Li, B. Li, H. Zhan and G. Li, Sci. Rep., 2016, 6, 29230.

28 M. Misra, N. Singh and R. K. Gupta, Catal. Sci. Technol., 2017, 7, 570-580.
29 J. Prakash, S. Sun, H. C. Swart and R. K. Gupta, Appl. Mater. Today, 2018, 11, 82-135.

30 A. Tyagi, K. M. Tripathi, N. Singh, S. Choudhary and R. K. Gupta, RSC Adv., 2016, 6, 72423-72432.

31 N. Singh, K. Mondal, M. Misra, A. Sharma and R. K. Gupta, RSC Adv., 2016, 6, 48109-48119.

32 M. Misra, R. K. Gupta, A. Paul and M. Singla, J. Power Sources, 2015, 294, 580-587.

33 N. Singh, J. Prakash, M. Misra, A. Sharma and R. K. Gupta, ACS Appl. Mater. Interfaces, 2017, 9, 28495-28507.

34 S. Dinda, F. L. Yap, V. Suresh, R. K. Gupta, D. Das and S. Krishnamoorthy, Aust. J. Chem., 2013, 66, 1034-1038.

35 R. K. Gupta, D. Y. Kusuma, P. Lee and M. Srinivasan, ACS Appl. Mater. Interfaces, 2011, 3, 4619-4625.

36 R. K. Gupta, S. Krishnamoorthy, D. Y. Kusuma, P. S. Lee and M. Srinivasan, Nanoscale, 2012, 4, 2296-2300.

37 R. K. Gupta, G. Ying, M. Srinivasan and P. S. Lee, J. Phys. Chem. B, 2012, 116, 9784-9790.

38 N. Singh, R. K. Gupta and P. S. Lee, ACS Appl. Mater. Interfaces, 2011, 3, 2246-2252.

39 N. Singh, A. Ponzoni, R. K. Gupta, P. S. Lee and E. Comini, Sens. Actuators, B, 2011, 160, 1346-1351.

40 S. Rahim, S. Khalid, M. I. Bhanger, M. R. Shah and M. I. Malik, Sens. Actuators, B, 2018, 259, 878-887.

41 S. Rahim, S. A. Ali, F. Ahmed, M. Imran, M. R. Shah and M. I. Malik, J. Nanopart. Res., 2017, 19, 259.

42 C. Deraedt, L. Salmon, S. Gatard, R. Ciganda, R. Hernandez, J. Ruiz and D. Astruc, Chem. Commun., 2014, 50, 1419414196.

43 F. Frederix, J.-M. Friedt, K.-H. Choi, W. Laureyn, A. Campitelli, D. Mondelaers, G. Maes and G. Borghs, Anal. Chem., 2003, 75, 6894-6900.

44 A. M. E. Badawy, T. P. Luxton, R. G. Silva, K. G. Scheckel, M. T. Suidan and T. M. Tolaymat, Environ. Sci. Technol., 2010, 44, 1260-1266.

45 H. Tyagi, A. Kushwaha, A. Kumar and M. Aslam, Int. J. Nanosci., 2011, 10, 857-860.

46 V. J. Gandubert and R. B. Lennox, Langmuir, 2005, 21, 65326539. 